\title{
A INTER-RELAÇÃO TRABALHO-SAÚDE MENTAL: UM ESTUDO DE CASO
}

Edith Sellgmann Silva

Professora do Departamento de Fundamentos Sociais e Jurídicos da EAESP/FGV.

* RESUMO: $A$ autora, após sintetizar algumas das vertentes de estudo e conceitos atuais na temática da inter-relação trabalho-saude mental, apresenta um estudo de caso individual. Trata-se do caso de um mecânico industrial do setor siderúrgico que desenvolveu um quadro psicopatológico. A evolução de manifestações de fadiga crônica e desencadeamento de uma crise mental aguda são examinadas em suas correlações ao histórico de vida e trabalho e a dinâmicas referidas às condições e à organização do trabalho no emprego atual.

* PALAVRAS-CHAVE: Saúde mental, saúde mental ocupacional, saúde do trabalho, psicopatologia do trabalho.
* ABSTRACT: The author, after sinthesizing some of the study sources and present concepts concern to the interrelation between work and mental health, shows a study on an individual case. It deals with a case of an industrial-mechanic who works in the siderurgical area and had developed psycopathologic manifestations. The evolution of the chronic fatigue expressions and the unchain of a sharp mental crisis are examinated on their co-relations with the work life, as well as with the dynamics related to the work conditions and organization in the present job.

* KEY WORDS: mental health, occupational mental health, work health, work psychopathology.

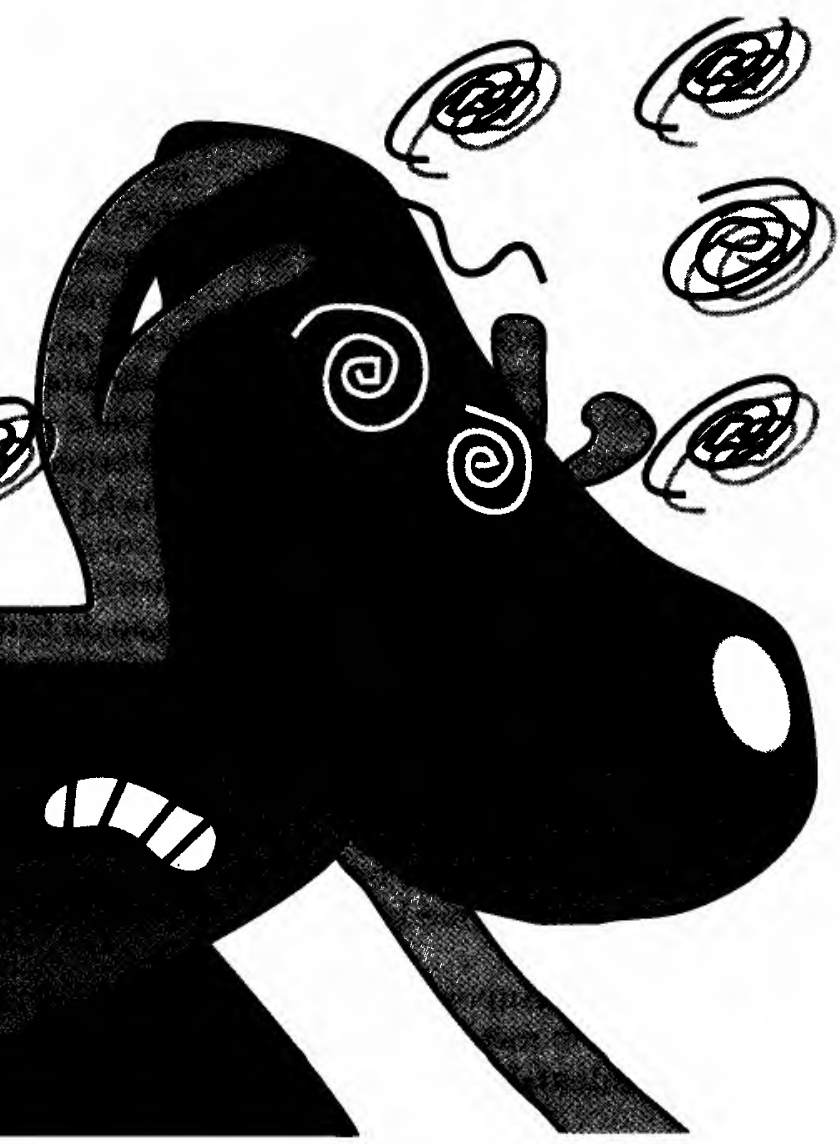




\section{SAÚDE MENTAL E TRABALHO}

Os estudos referentes à qualidade de vida no trabalho cada vez mais vêm enfatizando a importância das inter-relações trabalho-saúde mental. A temática vem despertando interesse tanto entre os administradores da área de saúde quanto entre aqueles que planejam e gerenciam o trabalho no setor industrial e em diferentes tipos do setor terciário.

Os fatores subjetivos e psicossociais vêm sendo identificados na análise de acidentes de trabalho, do absenteísmo e na busca de explicações para disfunções diversas, bloqueios de comunicação, perdas de qualidade do produto e incidentes que prejudicam o processo produtivo.

Nas estatísticas brasileiras de auxílio-doença, o peso da morbidade psiquiátrica é aspecto relevante e notório. $O$ desgaste mental, incidindo em empregados experientes e responsáveis, ocasiona incalculáveis perdas, tanto em termos humanos quanto financeiros, simultaneamente expressos a nível da saúde e da produção.

Para os planejadores que atuam na programação da prestação de serviços de saúde, fica atualmente evidente a necessidade de estabelecer vias de integração entre as atividades de Saúde Mental e as de Saúde do Trabalho. Isso significa, entre outros aspectos, introdução de novos conteúdos nos programas de treinamento destinados ao pessoal de Saúde.

Por outro lado, tanto os profissionais de Saúde que atuam junto às empresas quanto os que desenvolvem atividades em órgãos da Previdência Social encontram freqüentemente situações cujo esclarecimento epidemiológico ou clínico, no que diz respeito a transtornos mentais, exige conhecimentos de Psicopatologia do Trabalho.

Do mesmo modo, na administração de empresas e na administração pública, a identificação de aspectos ambientais e organizacionais implicados na gênese ou desencadeamento de "doenças", tanto humanas quanto da produção, poderá ser mais acurada a partir de um novo enfoque.

O contexto social e o "território" próprios da empresa no qual decorre o cotidiano do trabalho e das relações interpessoais encontram-se em constante inter-relação. Assim, os reflexos das conjunturas se fazem sentir no interior das empresas, da mesma forma que o mundo do trabalho irá repercutir externamente.

Situações de mal-estar. Situações de tensão vivenciadas coletivamente se expressam em adoecimentos individualizados. A Epidemiologia oferece metodologia e instrumentos para estudar associações entre as variáveis de diferentes esferas dos ambientes (físico e social) e o aparecimento de diferentes patologias. As observações e registros realizados nos serviços de atendimento médico, juntamente com registros de absenteísmo e outras verificações, permitem identicar, a partir de uma perspectiva epidemiológica, duas situações: 
1. Ocorrência elevada de crises. Existem situações no interior das empresas - geralmente identificadas simultaneamente pelas gerências, setor de RH e serviços médicos das empresas que os possuem - em que crescem as tensões e suas repercussões a nível dos desempenhos, dos conflitos interpessoais e da eclosão de queixas "nervosas" ou psicossomáticas. Podemos, aí, caracterizar uma elevação de episódios clínicos agudos: "crises nervosas"; crises de taquicardia; episódios de mal-estar rotulados nos serviços médicos como "distonia neurovegetativa"; crises de hipertensão arterial e mesmo infartos cardíacos fulminantes. Do ponto de vista epidemiológico, pode-se então caracterizar aqui uma situação de maior incidência de episódios agudos. (Lembrando que o termo incidência diz respeito ao surgimento de "casos novos" de doença dentro de determinado período de tempo.)

Essa situação coresponde a circunstâncias nas quais pressões especialmente fortes exarcebam o cansaço e a tensão emocional dos empregados. É o que pode ser registrado em períodos correspondentes à intensificação de produção ou quando são anunciadas transformações tecnológicas e / ou organizacionais. Apresentam geralmente um caráter reativo. Circunstâncias de ordem conjuntural - como recessão econômica - nas quais aumenta a insegurança no emprego e efetivamente muitos assalariados são dispensados, representam igualmente momentos em que se intensificam exigências que atingem a esfera mental. Assim poderá ocorrer um aumento de atendimento de crises de ansiedade e de suas diversas expressões psicossomáticas - episódios de taquicardia, sufocação, diarréias nervosas etc., no setor médico de uma empresa determinada na qual estejam ocorrendo grandes modificações. Mas também em setores de produção, regiões ou países afetados por crises, os registros psiquiátricos refletem tais impactos. ${ }^{1}$ Em tais situações, também o aumento das tentativas de suicídio merece especial atenção.

1. MCQUEEN, D.V.' e SIEGRIST, J. Social Factors in the etilogy of chronic disease: an overview, Soc. Sci. Med. 6:35367, 1982; SELIGMANN SILVA, Edith. "Saúde Mental e Trabalho". In TUNDIS, S. e COSTA, N. (org.) Politicas de Saúde Mental no Brasil, p. 21788, Ed. Vozes/Abrasco, 1987; . Crise Econômica,

Trabalho e Saúde Mental. In ANGERAMI, W. (org.) - Crise, Trabalho e Saúde Mental no Brasil, São Paulo, pp. 54-132, Ed. Traço, 1986;

Desgaste Mental no Trabalho Dominado (Em Publicação).

2. Prevalência: termo utilizado em Epidemiologiapara designar a proporçăo de casos de determinada doença em uma dada populaçãa em determinado mo. mento ou período delimitado.
2. Situações em que há maior prevalência ${ }^{2}$ de distúrbios da esfera "psi". Vêm sendo estudadas em determinados setores de atividades formas de organização do trabalho, ou, ainda, com respeito a algumas profissões - nas quais os riscos mentais têm sido constatados com maior evidência. Vários desses estudos correlacionam a estrutura de morbidade "psi" a constelações de fatores de risco que interagem na situação laboral, tornando possível identificar os processo que atuam a nível do cotidiano, sincronicamente.

Ao mesmo tempo, é indispensável considerar que existe também um caráter cumulativo em muitos destes processos, quando examinados em perspectivas longitudinal, ao longo do decorrer do tempo - quer na biografia dos indivíduos, quer na história dos coletivos de trabalho. Para o entendimento dos processos em causa, o exame em perspectiva diacrônica, por conseguinte, se torna necessário. Especialmente nos estudos que investigam as razões pelas quais em determinadas empresas ou áreas específicas das mesmas, ou mesmo em certas ocupações, ocorrem maiores índices de alcoolismo, depressões e transtornos psicossomáticos, análises longitudinais têm proporcionado considerável esclarecimento. Assim, o histórico de uma empresa - em seus vários momentos organizacionais e tecnológicos - poderá explicitar em muito a situação psicossocial do coletivo de seus empregados.

A importância da biografia ocupacional foi especialmente bem estudada em investigações referidas à doença coronariana e ao enfarte do miocárdio, em que a nível das trajetórias de vida laboral puderam ser 
identificados os processos psicossociais conectados ao trabalho que tiveram lugar cumulativamente. ${ }^{3}$ Portanto, também para a abordagem clínica, a consideração da dimensão psicossocial do trabalho oferece subsídios que poderão ser utilizados tanto para fins diagnósticos quanto para objetivos preventivos, uma vez identificadas as constelações de risco e as possibilidades de intervenção.

\section{A COMPLEXIDADE DA TEMÁTICA}

Numa tentativa de sintetizar a complexidade dos fenômenos que conectam a instância psíquica individual e os diferentes âmbitos das esferas sociais nos quais se insere, vale considerar o que segue.

a) Existe uma interatuação dinâmica e continuada entre instância psíquica (individual) e experiência laboral (coletivo micro-social);

b) As dinâmicas que se processam articulam vivências individuais, que pela via de intersubjetividade atingem a instância coletiva.

c) O sofrimento vivenciado pelos indivíduos, através dessas conexões, dá ensejo para que a nível coletivo duas formações tenham lugar, dando origem a duas expressões: o sistema coletivo de defesa contra o sofrimento e o sistema de resistência emancipatória e de compromisso ético.

Esses dois sistemas coletivos foram profundamente estudados por Dejours ${ }^{4}$, que a partir de 1980 publicou uma série de estudos sobre o assunto, em textos que vêm marcando os desenvolvimentos teóricos da Psicopatologia do Trabalho de enfoque psicanalítico. Pharo ${ }^{5}$ realiza importante elaboração teórica sobre a intersubjetividade, a cujo nível se desenrolariam, por exemplo, os fenômenos de intercompreensão e interatividade, nos espaços "micro" do cotidiano laboral. Nesses espaços se constrõem uma ética e uma consciência, vinculadas a significados vivos na consciência dos agentes, segundo o mesmo autor. Dejours $^{6}$, ao analisar os fenômenos intrapsíquicos, os intersubjetivos e as configurações assumidas a nível "micro" pelos coletivos de trabalho, não deixa de apontar que as sobredeterminações da advindas do âmbito macrossocial estão presentes, quando reafirma que "a organização do trabalho se encontra, em definitivo, sobredeterminada pelas relações sociais de trabalho"?

Evidentemente, essa visão teórica com respeito à natureza e à dinâmica dos fenômenos em que o sofrimento pode ou não dar lugar a manifestações de doença, opõe considerável dificuldade a um estudo de "riscos mentais do trabalho" dentro da abordagem epidemiológica. A propósito, Dejours considera que diferentes abordagens - inclusive a epidemiológica e todas as que se baseiam no conceito de stress - não são apropriadas" para elucidar as complexidades das condutas singulares, das construçôes coletivas e das articulações entre os dois registros do singular e do coletivo". ${ }^{7}$ As pesquisas destinadas a estudar estes processos devem ser, conforme o autor, de caráter eminentemente qualitativo.

Em uma outra perspectiva teórica, categorizações de "fatores psicossociais de risco" têm sido utilizadas pelos diferentes autores e pesquisadores que se filiam à corrente que estuda repercussões do trabalho na saúde psicossocial em termos de stress. Vale destacar a revisão realizada por $\mathrm{Kalino}^{8}$ dentro desta perspectiva, bem como as investigações e modelos desenvolvidos por karasek e Theorell ${ }^{9}$, assinalando, ainda, que considerável ampliação do conceito tradicional de stress poderá ser verificada nestes estudos.
3. MASCHEWSKY, Wemer. The State of Stress and Strain Research. International Institute for Comparative Social Research, Berlin, 9llVG, Papers, 1982; DEJOURS, Christophe. "Itineraire Theorique on Psychopathologie du Travail", Prevenir, no20, Marseille, 1990.

4. DEJOURS, C., DOPPLER, F e LOGEAY, $P$. "Psychanalise et Travail:InterventionauColloque "Champ Social et Inconscient". Centre Nacional de la Recherche Scientifique (C.N.R.S.), p.9, 1983; Christophe

Aloucura do trabalho. Ed. Oboré/ Cortez, p. 163, 1987; "Travial et Santé Mentale:del'Enqueteal'Action", Premieres Journées de Pyschologie du Travail-Paris, 1989; . "Itineraire Theorique on Psychopathologie du Travail", Prevenir, no 20, Marseille, 1990.

5. PHARO, Patrick. Questions à la Psychopathologie du Travail. In DEJOURS, C. (org.) Plaisir et Souffrance dansle Travail, Tome II, p. 11-27, Ed. del'AOCIP,Paris, 1988.

6. DEJOURS, Christophe. "Itineraire Theorique on Psychopathologie du Travail", Op. cit.

7. Tradução e grifo da autora.

8. KALINO, R. Assesment of occupactional stress. In O.M.S. Epidemiology of occupational health-Copenhagen. European Series, $n^{2} 20,1987$.

9. KARASEK, R, e THEORELLI, T. Healthy Work-Basic Books, New York, Inc., 1990. 
Essa abordagem tem sido compatibilizada com estudos epidemiológicos, que continuam, não obstante, oferecendo muitos desafios para atender a complexidade das interações envolvidas. Esforços a respeito têm sido desenvolvidos por diferentes pesquisadores ${ }^{10}$

Nos estudos centrados na análise das repercussões de trabalho, em termos de desgaste, os aspectos sociais de diferentes âmbitos macrossociais da empresa e das estratégias de controle que esta imprime à organização do trabalho, têm merecido atenção especial.

Outras investigações ainda têm se detido no estudo da cultura organizacional.

A extensão e complexidade da temática exige que se considere um campo interdisciplinar para tais estudos: o campo da Saúde Mental do Trabalho.

\section{ASPECTOS NA INTER-RELAÇÃO TRABALHO-ESFERA MENTAL}

Os componentes da instância trabalho que estão envolvidos na dinâmica originadora destas perturbações pertencem a diferentes categorias e se inserem em diferentes níveis que vão do macrossocial ao individual e geralmente interatuam de forma

Os avanços tecnológicos cada vez mais aumentam as exigências cognitivas, determinando esforços mentais sempre maiores.

complexa. Cabe também dizer que esses componentes e os fenômenos em que tomam parte têm sido estudados em distintas abordagens teóricas, que já constituem ampla literatura especializada. Portanto, apenas será possível delinear aqui algumas informações sucintas sobre alguns dos aspectos em causa.

\section{0 sistema coletivo de defesas contra o sofrimento}

Conforme os estudos realizados por Dejours e assumidos pelo grupo que, ao lado deste autor, vem desenvolvendo importante sistematização da Psicopatologia do Trabalho, estas defesas coletivas não correspondem à lógica dos Setores de Medicina e Segurança do Trabalho. Estando em grande parte voltadas para tornar suportável e possível a permanência em situações perigosas de trabalho, caracterizam-se pela inversão e pela eufemização. Assim, no caso de situações que ameaçam a integridade física do trabalhador, este assume um papel ativo e desafiante em relação ao perigo, que pode ser também depreciado e ridicularizado. Isso explica a freqüência da não utilização de Equipamentos de Proteção Individual (EPIs), por exemplo, bem como da prática de certas "brincadeiras" em que há evidente conotação de exorcização do perigo. ${ }^{11}$ Evidentemente, esta explicação do não uso dos EPIs não se opõe a outras razões muito objetivas - como o desconforto e até a inadequação que muitos destes equipamentos representam para garantir os objetivos de proteção.

10. KARASEK, R. \& THEORELLI, Op. cit.; SELIGMANN SILVA, Edith. Metodologia de Pesquisa em Saúde Mental do Trabalho. Relatório de Pesquisa/CNPQ, 1984/85.

11. DEJOURS, Christophe, $A$ loucura do trabalho. Op. cit.

\section{Aspectos vinculados à natureza e ao conteúdo de tarefas}

Existem tarefas que por sua natureza e conteúdo envolvem a esfera psicoafetiva. Os exemplos poderiam ser numerosos. Lembremos as situações que envolvem riscos para a própria vida ou integridade física; as que exigem permanente e intenso auto-controle emocional; as que 
implicam em elevadas responsabilidades com vidas humanas, com valores vultuosos ou com a própria continuidade da produção.

\section{A estrutura temporal do trabalho}

Abrange distintos aspectos temporais como: a duração das jornadas, sua distribuição em termos diurnos e noturnos e a organização de turnos; distribuição das folgas, considerando também quais os dias da semana em que ocorrem (pelo óbvio interesse de que possam coincidir com fins-de-semana); dispositivos referentes às pausas (quantidade, duração e qualidade); flexibilidade ou prescrição rígida dos ritmos; pressões de tempo referidas ao desempenho de etapas das rotinas de trabalho. No caso do regime de trabalho em turnos alternados também denominados turnos de revezamento - inúmeros estudos têm sido realizados comprovando a nocividade deste sistema para a saúde, com especial ênfase na forma como é atingida a saúde psicossocial e afetada a fisiologia neuroendócrina e digestiva. ${ }^{12}$

\section{A densidade do trabalho em especial a densidade das atividades cognitivas}

Este aspecto vem merecendo muita atenção, na medida em que os avanços tecnológicos cada vez mais aumentam as exigências cognitivas, determinando esforços mentais sempre maiores. Na medida em que essas atividades se desenvolvem no decorrer de jornadas longas e são submetidas a pressões de produtividade, ocorrem repercussões em termos de fadiga e de irritabilidade, que se tornam profundamente negativas. Fica patente nesta observação a necessidade de estudar de maneira conjunta os diferentes elementos da situação de trabalho, visto que se torna insuficiente estudar o volume de atividade mental exigido, sem considerar a dimensão temporal na qual incide tal exigência. ${ }^{13}$

\section{O controle}

É um aspecto que incide fortemente na subjetividade e, simultaneamente, a nível do coletivo de trabalho. Há que considerar o controle como uma moeda de duas faces: a do controle que é exercido sobre o assalariado e a do controle que este exerce sobre a realização de suas próprias atividades laborais. A primeira face, é a dos níveis e formas de dominação, a segunda, corresponde ao espaço de autonomia dentro do qual podem ser tomadas decisões e aplicados os potenciais criativos.

Vale assinalar que nas empresas ditas modernas, a sutileza do poder organizacional associa o incremento do controle exercido sobre o assalariado aos estímulos que, dentro do espaço de autonomia, conduzam ao aumento da produtividade e das inovações que possam favorecer os interesses da empresa, ao mesmo tempo que deixam um "espaço de prazer" ao empregado, promovendo assim sua coaptação, num processo bem analisado por Pages e colaboradores. ${ }^{14}$

Formas sofisticadas de controle surgem também nos processos automatizados e computadorizados. A partir do controle embutido nos próprios equipamentos, manifestações psicológicas de insegurança são muitas vezes suscitadas, podendo assumir intensidade $e$, inclusive, dar lugar a vivências de estar sendo perseguido. A ansiedade vinculada a tais situações poderá acarretar não apenas a intensificação da tensão e da fadiga mental, como ocasionar inadequação das respostas em situações de emergência. $\mathrm{O}$ dispositivo que funciona como "controlador invisível" muitas vezes nem chega a ser identificado pelos emprega-
12.PÉPIN, M. L'Organisation du Travail Posté, Paris, Ed. de l'Anact, 114 págs, 1987.

13. WISNER, Alain. La densité du Travail. In WISNER, A. Testes Generaux, IV - 1981, 1985, pp. 43-45, Paris, 1986.

14. PAGES, M.; BONETTI, M.; GAULEJAC, V. EDESCENDRE, D. O Poder das Organizações, São Paulo, Ed. Atlas, 234 págs., 1987. 
dos, o que torna a vivência de estar sendo vigiado particularmente inquietante.

Necessidades psicológicas

O atendimento referente a diferentes necessidades psicológicas fortemente vinculadas à preservação da identidade social, em valores essenciais que muitas vezes se reportam à própria dignidade, precisa ser levado em conta. Mencionaremos apenas uma dessas necessidades como exemplo: a importância de perceber reconhecimento social na situação de trabalho.

Nas situações em que, ao invés de um reconhecimento social positivo, o trabalhador se sente como alvo de rejeição, o enfrentamento desta situação se torna especialmente penoso e, freqüentemente, configura ameaça à saúde mental.

\section{Aspectos do ambiente físico, químico e biológico do local de trabalho}

Suas repercussões na esfera mental se fazem quer diretamente, quer pela mediação da organização do trabalho, sempre que imposições de maior tempo de exposição a condições desfavoráveis, intensificação de ritmos de trabalho e outros fatores organizacionais atuem determinando, inter-relacionadamente, a dimensão dos agravos. Podemos apresentar alguns exemplos:

a) O trabalho em temperatura elevada demanda maior incremento de esforço para a concentração da atenção. Quanto maior a jornada de trabalho, mais intensa será também a fadiga mental, juntamente com a geral.

b) A ação neurotóxica é proporcional não apenas à concentração das substâncias tóxicas, mas também à duração da exposição e à intensidade do ritmo de trabalho. ${ }^{15}$

c) Os riscos de contaminação por microorganismo em laboratórios, hospitais e nos Serviços de Saúde em geral, são agravados quando a organização do trabalho apresenta exigências em que se fazem sentir pressões de tempo, diversificação de tarefas com dissociação da atenção e conseqüente diminuição das precauções. Deve ser acrescentado que a própria percepção de tais situações de risco resulta em considerável ansiedade.

\section{A singularidade individual}

O exame das inter-relações trabalho-esfera mental, evidentemente não pode deixar de lado o indivíduo, sua personalidade e a singularidade de seu histórico pessoal de vida e trabalho.

O exame das situações individuais remete à prạ́tica clínica, onde o médico se defronta com o desafio de incluir a instância trabalho. Quais os aspectos do trabalho que devem ser investigados, em cada situação particular, a nível individual, para caracterizar os riscos "psi" e sua correlação com o quadro clínico? Acreditamos que a exposição de um estudo de caso individual possa ser útil para uma reflexão a respeito. 


\section{UMA HISTÓRIA DE "CRISE DE NERVOS"}

\section{O entrevistado - situação por ocasião da entrevista}

O Sr. Júlio é um homem de 55 anos. Mecânico de manutenção em empresa de setor siderúrgico, da qual se aposentou por tempo de serviço, há um ano. Reside com a esposa e quatro filhos em uma casa de alvenaria, de sua propriedade, que possui sala, dois quartos, varanda, cozinha, banheiro e um pequeno quintal, Nasceu no interior do Estado de Santa Catarina. Reside em São Paulo há 31 anos.

As entrevistas foram realizadas na casa do Sr. Júlio, sendo que durante parte do tempo a esposa e duas filhas participaram.

\section{História de trabalho}

"Comecei a trabalhar aos treze anos, no pastoreio de ovelhas e carneiros, no mesmo lagar que meu pai era empregado. Fiz exército e depois de servir tornei a voltar pra fazenda. Mas achei que ali não ia ter futuro para mim. Eu tinha vontade de estudar, de progredir. Dai, com 24 anos, vim para Säo Paulo. Naquele tempo era fácil arrumar serviço. Primeiro trabalhei três meses numa padaria, de balconista. Depois, fui pra uma tecelagem: e foi lá, no cilindro da máquina de rolamentos, que perdi três dedos da mão esquerda. Foi porque um menino lá do serviço apertou sem querer um botão da máquina. Foi nessa tecelagem que eu fui registrado pela primeira vez, trabalhei lá seis meses, como tecelão e depois também na manutenção mecânica. Quando perdi os dedos, fui pro seguro. E quando ooltei de tratamento, fui mandado embora, não me aceitaram mais. Fiquei uns seis meses sem trabalhar, mas tive oportunidade de fazer curso de mecânica, um curso pequeno. E em 1951 entrei para Sideruirgica L., como porteiro e apontador. Fiz esses serviços por três anos. Apontador é o que anota as horas trabalhadas. Quando descobriram que eu entendia de máquinas me colocaram como operador de máquinas de ar comprimido, na Aciaria. Fiquei nesse serviço da Aciaria durante 15 anos. Mas eu conecei a fazer um curso por correspondência, de graça, durante dois anos. Foi por informação de um técnico estrangeiro que trabalhou na Siderúrgica que eu consegui fazer esse curso e passei depois pra mecânico. Ea Siderírgica bem que ganhou com isso, porque deixou de pagar a firma que fazia antes a manutenção dos compressores, pro trabalho passar a ser feito por nim. E eu fico recebendo um pouquinho mais só, do que o que recebia antes. Eu tinha chegado a ser chamado, convidado pra trabalhar na firma estrangeira que fazia a manutenção, depois que terninei o curso. Mas na firma L. prometeram me dar chefia e um grande ordenado. Fiquei e o prometido não foi cumprido. Só depois foi que me passaram pra contra-mestre, mas com muito menos salário do que tinham prometido". (Pausa) "Sabe, devido aos defeitos da mão, eu sabia que não arranjava lugar em qualquer firma e tive, na minha vida, que me sujeitar a passar muita humilhação. No meu trabalho, depois, ensinei muitos outros. Homens que chegavam apoiados pela diretoria, e que depois passaram a ser meus chefes, vários deles. Nesse tempo que eu fiquei como mecânico de compressores, eu tinha horârio de entrar mas não tinha hora de sair - era conforme o serviço que eu faria. Com tantos anos nessa firma e com tanta responsabilidade, cheguei apenas a subir muito pouco, a ser contramestre e ficar mais de cinco anos nessa função. 
A responsabilidade era grande - cuidar dos oito comrpressores e ainda controlar todo o material que chegava dos Estados Unidos pra fazer manufenção... Othe, eu acho que lá na empresa principalmente nos ultimos anos se aproveitaram muito do meu defeito na mão: não me promoviam. E isso também porque não gostavam quando eu protestnon. Eainda mais: de eu ter sido testemunha a favor de outros operários prejudicados pela firma. Pros que trabalhavam comigo eu ensinava tudo: o trabalho e os direitos que o operario tem - $e$ os homens da firma não gostavam disso. Houve um engenheiro estrangeiro que me perseguiu bastante, quis me mandar embora porque eu tinha feito unas criticas dos erros técnicos dele e também aos ataques que ele fazia contra os operários. Mas quando ele viu minha ficha, que eu tinha 18 anos e nenhuma advertência, não pôde fazer nada contra "mim".

\section{A atividade na manutenção - condições de trabalho}

"Esse trabalho era numa sala coberta, fechada. Ninguém suportava aquele calor. Depois colocaram lá quatro ventiladores, mais tarde seis. Melhorou o calor, mas piorou o barulho. E, na verdade, esses ventiladores nem foram colocados pra gente, foi mais pra aumentar o ar pros compressores. Cada compressor é uma máquing muito grande, maior que essa sala da minha casa. Eu tinha que consertar esses compressores. Quando näo havia nenhum problema pra consertar, a rotina era verificar cada 20 minutos os registros de agua, da temperatura e do oleo. Não dava pra agüentar muito tempo nessa sala dos compressores. O ar de lá era de um jeito que não era suficiente pra gente respirar. E o barulho era insuportável. Por isso, logo que lerminava o conserto ou de ver os registros, eu tinha que sair pra um local ali do lado de fora dessa sala. La ainda se escutavam os compressores, mas era methor. Me disseram que agora, depois que me aposentei, fizeram lá uma cabine fechada, pra pessoa que faz esse controle de cada 20 minutos.

Eu tinha um superior que era o responsavel. Quando o compressor tinha defeito, eu tinha que desmontar ele lá dentro da sala, com os outros compressores trabalhando en volta naquele barulho. E cu sentia cansaço, um mal-estar em todo corpo, ficava mal-humorado, a cabeça doendo, ali naquele serviço. A dor de cabeca era pelo barulho, eu sentia.

Mas eu não trabalhava so nos compressores e nos registros. Tinha muitas vezes que fazer manutenção também de outros equipamentos. Por exemplo, nos feriados, da ponte rolante.

Meu trabatho nos compressores era assim: quando um compressor tinha defeito, en tinha que desmontar aquela parte. Nos ultimos anos eu já não agüentava o barulho, não agüentava mesmo. E os encarregados sempre em cima da gente. Porque eles não tinham pessoas em número suficiente pra trabalhar ali, faltavam mecânicos. Punham ajudantes despreparados pra trabalhar, a gente tinha que estar junto o tempo todo, pro serviço não ficar mal feito. E tinha que ser tudo depressa! Que eles precisavam de ar nos fornos! E eles não sabiam trabalhar, isso fazia demorar mais, Mas o serviço não terninava às seis, a gente tinha que ficar 
até as oito, ou até mais tarde, às vezes até o outro dia. O horário nesse tempo - até o ano de 1980 - era de doze horas de trabalho, das 6 da manhã até as 18 horas, mas normalmente eu ficaza das 6 às 22 !

Quando testam compressores novos, pra medir quantas libras de ar o compressor vai usar, aquilo é terrível, nem com o protetor de ouvido resolve - atinge demais a audição da pessoa. Todo mundo corria pra fora nessas ocasiōes, só eu e o técrico que estava testando é que ficávamos.

As vezes eu ficava horas seguidas consertando um compressor. Era dificil passar uma semana sem consertos.

O médico otorrino me disse que no ouzido direito eu só tenho $10 \%$ de audiçâa. Na sala dos compressores, como eu já falei, o calor é muito forte. Mesmo querendo usar o protetor de ouvido, no verão era impossivel, porque o ouvido enchia de suor, aquilo irritava, era insuportável. E além do barulho dos compressores, que era constante, também tinha o seguinte: de repente, uma váloula do compressor estourava e a gente estremecia, tal era o barutho.

Ali na sala dos compressores tinha muita coisa pra aumentar o nervoso da gente. Perigo maior que já teve lá, foi um reservatório de ar que colocaram ali dentro. $E$ isso eu não me conformaza. Porque ai estava em perigo tanto a minha vida como a de todos os companheiros que trabalhavam comigo. Se por exemplo a válvula de segurança quebrasse, podia haver uma explosão. E morrer todo mundo ali. Eu reclamei, disse que era perigoso demais, que un reservatónio desses tem que ficar fora de ambiente fechado. Mas demorou um bom tempo para tirarem o reservatório de lá.

Outra coisa é a trepidação. Ali a trepidação é demais. Sentia ela dentro da cabeça - parecia que o cérebro estava também batendo a mesma coisa que a trepidação de fora. Era tão forte essa trepidação, que muitas vezes a gente ia esquentar a comida num fogareiro que tinha lá, chegava a cair tudo - marmitas, comida-derramava tudo e af é que a gente ficava nervoso mesmo e sem comer... E tem também um gás que dá sono na gente. Penso que esse gás pioraza a dor de cabeça, junto com o barulho, com o calor, com a trepidação. Eu cheguei a desmaiar duas vezes por causa do calor. O calor era tanto, o suor escorria, dava náusea esse calor, e fazia perder todo apetite. Dentro da sala dos compressores, o calor chegava a uns $50^{\circ}$. Num desses desmaios pelo calor, eu cai de cima dum compressor que eu estava consertando, machuquei muito a perna (mostra uma longa cicatriz). Nesse dia eu ji estava sentido ruim com o calor, mas queria terminar o serviço. Foi quando de repente deu a tonteira e eu caí lá de cima."

\section{A falta de peças}

"Um problema que preocupava era a falta de peças. Eles queriamo trabalho. E eu dizia -Mas eu não tenho peças pra trabalhar. Eles ficazam fazendo muita pressão em cima de mim, pro trabalho sair logo, e eu sem peças. Tudo isso afetava o meu sistema nervoso. Eu ia pra casa levando o problema na cabeça. Ficaua só pensando: Como é que vou fazer amanhã, se não tenho as peças que preciso pra consertar aquele compressor. Ficava só pertsando nisso e nem conseguia conversar direito com a familia. E perdia o sono...

Eu tinha que improvisar, que aproveitar peças velhas pra colocar. Os chefes não queriam mandar buscar o material que era necessário. Acho que era pra evitar despesas pra firma e desse jeito eles chefes ficarem com 
maior apoio da direção, conseguirem promoção e oantagens. Quanto menor despesa e maior produção, mais aumento pros engenheiros e pros outros chefes. Às vezes eu improvisava e dava certo, às vezes não dava. Eles queriam produção, $e$, depois, se o serviço não ficava bom, a queixa vinha contra mim... Se eu podia discutir esse problema com eles? Antes, não, ficava calado. Mas, depois daquela crise de nervos, mudei. E falava mesmo: vocês qucrem que o compressor trabalhe? Então comprem válvulas, canaletas, o resto do material que precisa, que eu ponho ele nowo!... E era muito mais trabalho por causa desse problema de falta de pegas novas: eu fazia o conserto num dia, com as peças velhas, poucos dias depois quebraza de nowo. Se o serviço desse certo, a vantagem era pra eles (os chefes) ficar com mais prestígio. Se não desse, a culpa era minha... Mas teve um dia que eu fui falar com un engenheiro meu conhecido que era do outro setor, mas era lambém da diretoria. Ele ficou admirado do que eu contei sobre as peças. Falou que nunca tinham tocado no assunto lá nas reunióes dos engenheiros. $E$, depois disso, ele foi falar com os outros, e coneçaram a comprar mais material que precisava."

\section{As pertubações sentidas}

\section{a) O sono perturbado e a irritação}

"Fu domia bem antes de trabalhar no turno (revezamento). Co" mecei a ter problema foi quando fui trabathar de três turnos e ficava no notumo. Não conseguia dormir bem de dia. Mas o problema maior de sono foi depois, quando passei pro horário de doze horas de trabalho... $\mathrm{O}$ problema de faltar o sono era quando eu ficava pensando no serviço e pensando na familia. Isso já quando eu trabalhava as doze horas seguidas. Dormia, acordava, rolava... Qualquer barulho - criança, carro passando - -tudo já me acordava. Nesta rua, os carros aceleram porque é uma subida, faz muito barulho.

"Quando passei a contramestre, a responsabilidade era muito grande. A qualquer hora, con sono ou já dormindo, winham ai na minha porta chamar: 'Tem uma máquina quebrada. Precisa ir lá consertar'.

Há uns dez anos atrás, eu já ficava assim um pouco nervoso, quando era na semana to turno da noite. Porque, sabe, quem trabalha de noite, nunca dorme bem de dia. E o barulho me irritava, o barulho do serviço, $e$, depois, mesmo em casa. As crianças - sabe cono é criança, criança é criança-querem brincar... E eu já irritava, sentia um pouco de netooso, mas não tanto como depois.

A senhora, quando chegou aqui esta manhã, ouvia essa música. (aponta para o toca-discos), estava tocando alto. Se fosse antigamente, se eu chegasse en casa e estivesse mísica alta, eu näo agüentava, eu estourava. Hoje não, podem tocar! Mas eles sofreram também, minha famitia sofreu, eles podem contar (faz movimento para se retirar da 
sala e deixa a entrevistadora com a esposa e as duas filhas que estão na sala. A entrevistadora insiste para que permaneça explicando a importância de que todos falem e se escutem. Ele permanece, mas demonstra sinais de inquietação).

Pra mim ela foi mãe, foi enfermeira, foi tudo (está se referindo à esposa). Eu agradeço estar vivo a Deus e a ela. Foi demais, o que eu passei e o que minha familia passou por causa desse nervoso meu. Fu ficaza desesperado, uma vez quebrei um copo d'água na boca, podia ter morrido na hora se não fosse a familia. Eu também brigava com os filhos por qualquer coisa. E eu amo eles demais! Se eles estavam aqui escutando misica, num domingo ou feriado, eu chegava e brigava com todo mundo. Eu já vinha perturbado, de vez em quando era mais forte o nervoso era preciso um vizinho vir socorrer, me levar correndo pro convênio, toda vez que minha mulher chamava, toda vez que ela via que já ia me dar o ataque nervoso. Lá no convênio me davan tuma injeçāo e eu voltaza pro trabalho. Convênio é assim mesmo: atendem e depois dizem: 'Vai embora, vai trabalhar."

Neste momento, a esposa toma a palavra:

"Ele ficava muito nervoso mesmo. Aqui em casa, teve uma vez uma crise muito forte, ficou muito nerooso, tentou abrir a gaveta pra tirar uma faca, e... era com ela (aponta para a filha mais velha)... até ela ficou traumatizada. (A filha começa a soluçar, passando a chorar convulsivamente). D.Ana, a esposa do Sr. Júlio, chora também. $O$ entrevistado abraça a filha, visivelmente emocionado, murmurando palavras de carinho). Minha filha... aquilo acabou ... näo tem mais nada! Não lembra o passado... Teu pai esta bom agora. Você ficou traumatizada mas eu não sabia o que estava fazendo. Uma pessoa quando tem o sistema nervoso abalado do jeito que eu estava, é claro que muitas coisas acontecem. Pior é se a pessoa não tem o amparo da familia. E eu, graças a Deus, tive a compreensão de vocês, paciência , carinho... Eu, pra mim naquele tempo não era homem, não era nada, nem animal. Eu não tinha possibilidade de raciocionar, o nervoso não deixava. E una pessoa quando não tem raciocínio, então o que é?... Eu não sabia que estaza maltratando vocês. E vocês me ajudaram, faziam de tudo, a comida na hora, o remédio na hora e sempre me agradando!"

Estamos vivendo um momento realmente dramático na entrevista. Muitas emoçôes vieram à tona, certamente acionadas pelas lembranças em que muita dor, violência e culpa estavam intimamente associadas.

b) Mágoas e emoçōes reprimidas

"Pessoas que eu ajudei, que começaram depois que já estava trabalhando lá há muito tempo, pessoas que eu entsinei como um professor ensina um aluno, depois, passaram a ser meus encarregados! E eu nunca passava daquilo. Por que? Eu sentia mágoa com essa situação, mas não reclamaza da injustiça. Mas foi indo, foi indo, me atacando tanto aquele sentimento, e eu calado, calado, calado. Pra não desabafar. Mas chegou um tempo que o esgotamento físico foi tanto, foi tanta perturbação, tanta a perseguição que eu não agüentei mais. Meu cérebro, meu corpo, meu sistema nervoso não agüentaram mais! E ai, chegou uma ocasião que en tive que ficar trabulhando 47 horas ern seguida, sem vir em casa. Foi quando deu a crise, porque eu não podia agüentar mais." 


\section{c) "A crise de nervos"}

"A Aciaria só pára cinco dias por ano: $1^{\circ}$ de janeiro, Sexta-feira Santa, $1^{0}$ de maio, 7 de setembro e Natal, é claro. Ficam lá só os forneiros eo pessoal das fossas. Mas as vezes, mesmo em um desses cinco feriados, eu tinha que ficar pra manutenção de outras partes que não pertenciam ao meu serviço.

Justo num feriado, houve um problema que parou a produção e foram chamar em casa à noite.

E foi nessa ocasião que eu tive que ficar 47 horas seguidas, ali nas fossas, sem vir em casa, naquele mau cheiro... Eu comandando a turma lá, todas aquelas pessoas metidas no meio daquelas fossas, de noite, frio... e eu sem poder fazer nada. Ai eu fui falar com o engenheiro, propus que uma turma trabalhe duas horas, duas outra outro grupo... Mas ele to engenheiro) dizia: 'Não, isso tem que ser feito rápido, com todo mundo'.

...E para mim aquilo doía. Os homens se revolfazam, revolfavam contra mim, que era o contramestre. E eu tinha que estar ali, com eles o tempo todo. O engenheiro e o encarregado geral iam dar voltas de carro, pra cá, pra lá...E os homens tendo que tirar aquela sujeira com os baldes, de uma altura de 15 metros, com as mãos, naquele mau cheiro terrivel... (explica) Agora existem duas bombas pra tirar aquela sujeira pra fora, mas antes não existiam essas bombas lá. Então eles tinham que tirar com baldes. O mau cheiro é porque isso é água de esgoto que vem pra represa da firma. Essa água é que é puxada pros fornos, pra fazer o resfriamento. Muitos, pra agüenlar tomam pinga antes de ir pra lá. E isso aumenta o perigo, eu ficava com medo que eles caíssem numa fossa daquelas, como já aconfeceu lá. E nesse trabalho, teoe caso também de pegarem doença - febre tifóide - que houve casos há uns anos atrás, de gente desse serviço de fossa. Então, eu me revoltava por aquilo, já fazia muito tempo. Porque sempre que eu dizia pro encarregado geral e engenheiro que nâo dava pra continuar aquelas condiçóes, aquele mau cheiro, eles só diziam que aquela água suja era necessária para dar a produção na laminaçẫo, nos formos de aço.. Falaram que quanto mais depressa os homens trabathassem, melhor pra dar essa produção. E que o mau cheiro fazia eles trabalharem rápido, querendo terminar logo... Quando terminamos de limpar tudo, o encarregado geral mandou ligar uma máquina e o rapaz que trabalhava nessa máquina não ligou a agua, porque a água ainda estava ruim. A máquina quase fundiu! (peto fato da água náo ter sido ligada). A diretoria chamou o encarregado e ele disse que não havia mandado ligar nada. E descarregou a culpa por cima de mim. No dia seguinte, ell estava fazendo um serviço; la em cima do equipamento, quando vieran me actsar. Eu fui ficando nervoso, ficando nervoso, até que estourei! Gritei, perdi o controle, até bati com uma ferramenta no serviço que eu tinha acabado de fazer, quebrei de novo! Se eu não tizesse capacete, tinha morrido, porque acabei caindo lá do alto de ponta cabeça! Dai me levaram pro ambulatório da firma, que nem morto, desmaiado! Depois me levaram para a clínica do convênio, figuei internado uns dias. Desde esse tempo, eu venho tratando dos nervos, com psiquiatra. Mas ainda passei muito tempo sentindo mal. Voltei pro seroiço, mas sempre aquele mat, me eneroando, enerzando, chegou a um ponto que cu já não podia andar sozinho, tinha medo, alguém da famflia tinha que ir junto. Dava em mim uma decepção fāo grande que me deu até vontade de morrer." 
d) "Sufocos" e desmaios

Esposa: "Essas quedas que ele dava, caía dura. E quando dava o nervoso, era demais, o nerooso dele."

OSr. Júlio prossegue: "Nesse tempa, eu sentia un aperto na garganta que dava sempre que eu via ou sofria injustiça... Quando eu estava nesse sistema nervoso, sentía sufocar, repuxar, os nervos do pescoço. Minha esposa fazia massagem no meu pescoço e isso melhorava. As vezes eu nem conseguin dormir sentindo esse repruxado no pescoço. Com o tratamento eu fui melhorando depois que fui entendendo que na minha garganta ficaza muita caisa que eu abafava".

\section{Tempo de trabalho, tempo de não-trabalho, tempo de viver...}

Trabalhei nos turnos de revezantento durante' os 15 anos que fiquei como operador. Cada tumo era de ot to horas, mas muitas vezes era mais. Depois quando passei pro serviço de manutenção tinha que trabathar doze horas todos os dias. No tempo do turno era ruim, ainda mais que nessa firma se traballha sete horas seguidos pra folgar só noo oitavo dia. E só cada 40 dias é que tem uma folga um pouco maior, que da pra sair tum pouco depois de iescansar. Eu gostaza de ir nadar em

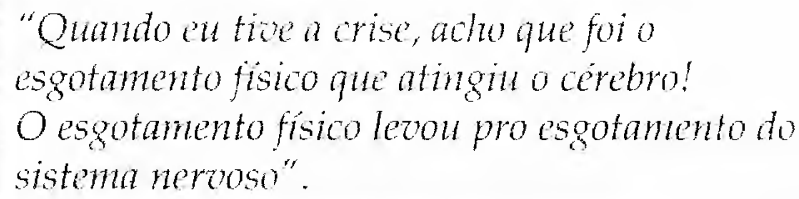

Santos, nessa folga grande. Nunca fui de ficar num bar. Às vezes ia num clube que tinha lá na firma, no tempo do turno e lá en jogava bocha, dominó, distraía um pouco. Agora nem sei mais se tem esse clube, porque quando passei a trabalthar doze horas por dia, näo deu mais tempo pra ir lá, não deu mais tempo pra visitar meus irmãos, acabou tudo deixei as amizades eos divertimentos. E fui me isolando até aqui em casa, quando o nervoso foi ficando demais. Io nem faloor quase com os filhos. E sei que o meu sistema nervoso afetou o sistema nervoso da minha mulher também! E piorou depois de minha crise!"

D. Ana acrescenta: "Tive que procurar médico è tornat remédio pra dormir".

\section{Buscando explicaçōes}

"Acho que o que influtu muito pro meu sistema newoso foi o barutho dos compressores. Mats era o barulho, mas o horário dos turnos também influitu muito, wais atnda quando trabalhava doze horas seguidas. Es senti mais cansaço al, também por outro motivo: nos thês tumos, eu só era operador, o mecôntico é que tinha que cuidas das peças. E depois, nas doze horas, eu era o responsátel. E o que abalou muito, também, ara o que os encarregados fazian connigo. Sempre em cima da gente, petindo pressa, mais produçăo.

Quando eu tive a crise, acho que for o esgotamento fisico que atingit o cérebro! Q esgatamento físico levou pro esgotamento do sistema nervoso. 
Sei que o serviço foi que influiu no meu sistema nervoso.

Saía de lá, me sentindo nerooso. Antes, eu era alegre, contador de piadas. Ultimamente vivia mal humorado com a familia -prios colegas. Fui notando em mim mesmo a diferenca, e os outros também notaram. Diziam até: porque subiu mais um pouco, está assim, de cara fechada. E não era nada disso. Se eu escutava música quando estava chegando en casa, já tapaza os ouoidos e ia embora reclamando: Não fico em casa, já vem vindo aquele acesso de nervos, vou embora...

Esgotamento físico me atingiu também. Esgotamento fisico é que a gente vai trabalhando, trabalhando $10,20,30$, até 40 horas em seguida, mal alimentado, nem dá tempo de comer, a gente esgota. E o esgotamento físico atinge o sistema nerooso. O sistema nerooso $e$ uma coisa que ataca todos os órgãos do corpo: bexiga, estômago, cérebro, garganta".

\section{COMENTÁRIOS}

\section{Leitura de uma sintomatologia}

O conjunto de sintomas revelado no depoimento do Sr. Júlio e as condiçoes de trabalho por ele referidas conduzem, num primeiro momento, no reconhecimento do cansaço crônico, isto é, da síndrome de fadiga patológica. Pois estão presentes as manifestações mais importantes da síndrome: a vivência do cansaço acumulado, as perturbaçōes do sono, dores em várias regiōes do corpo, perda de apetite, irritabilidade, desânimo, dores de cabeça.

Ainda outras manifestações, entretanto, são acrescentadas pelo relato. Os desmaios estão neste caso. E o Sr. Júlio possibilita certo esclarecimento da causalidade dos mesmos, quando sua própria percepção os distingue em "desmaios pelo calor" e "desmaios pelo nervoso".

Entretanto, não é possivel de uma forma imediatista formular explicações que reduzam o entendimento da instalação da sintomalologia a relaçóes diretas de causa e efeito.

Vo estudo do caso do Sr. Júlio, além do cansaço acumulado, é necessário reconhecer o papel da coerção vivenciada pelo entrevistado, da frustração de suas expectativas de ascensão funcional, bem como dos outros fenômenos psicológicos e psicossociais que se desenvolveram vinculadamente à sua vida e ao seu trabalho.

Assim o estudo descritivo de uma sintomatologia polimorfa como a apresentada pelo Sr. Júlio pouco nos dirá sc não houver, simultaneamente, uma tentativa do comprexender a complexa dinâmica que preside à instalaçào dos sintomas e à evolução do quad ro psicopatológico. Nesta dinâmica, há que considerar os seguintes conjuntos de aspectos: determinaçóes principais do histórico pessoral e da inserçăo laboral do Sr. Júlio (perspectiva diacrônica, isto ć, longitudinal); aspectos organizacionais e ambientais da situação de trabalho; defesas psicológicas.

1.1. Exame de algumas determinaçōes numa perspectiva longitudinal

Os estudos de casos individuais nos permitem examinar situações 
que, subordinadas a determinações coletivas de diferentes âmbitos, evoluem seguindo linhas particularizadas pelas singularidades de cada histórico pessoal.

OSr. Júlio nos trouxe a visão de sua vida laboral e das inter-relações da mesma com seu cotidiano e sua perspectiva existencial. Entretanto, o que ele nos transmitiu ao longo da entrevista, longe de ser um quadro estático, assumiu o aspecto dinâmico de uma experiência marcada por transformações. Permitiu-nos entender como suas próprias perspectivas em relação a seu próprio projeto de vida foram sofrendo modificações no decorrer do tempo. A maneira pela qual fluiu a entrevista permite perceber a complexidade das interações que foram se processando, entre diferentes aspectos do trabalho, da vida extra-laboral e da pessoa Júlio.

O depoimento ilumina uma dinâmica que envolve fenômenos distintos, que se inter-relacionam para constituir novos fenômenos, os quais vão desembocar

ora em desgastes ora em defesas e/ou resistências, alterando as vertentes mental, psicossocial e psicossomática da saúde do entrevistado.

Em sua trajetória pessoal de vida laboral e nas condições organizacionais e ambientais de trabalho que foi vivenciando ao longo Na lógica da empresa o princípio de que a produção não pode parar se sobrepõe às necessidades e limites da condição humana do agente da manutenção, conduzindo a uma prática em que não ocorrem pausas, as refeições são sacrificadas, os ritmos se aceleram e a jornada se prolonga até que seja sanado o mal que interrompeu a produção.

do tempo o Sr. Júlio desenvolveu suas próprias maneiras de lidar com as contingências particulares a que se via submetido. Na busca de um entendimento do papel que tiveram estas contingências na constituição do sofrimento mental do entrevistado, um primeiro momento de análise nos permite visualizar a importância assumida por três determinações que marcam sua situação laboral:

A primeira determinação é a que deriva do fato de ter sido mutilado por um acidente de trabalho ainda na juventude. Muito cedo percebeu que seu campo de opções ocupacionais ficava mais restrito a partir da perda de três dedos da mão esquerda. Assim, quando encontrou uma empresa que o aceitou, tudo fez para ser valorizado. Buscou, simultaneamente, garantir sua permanência na empresa e obter possibilidades de uma ascensão funcional. Encontrou o caminho utilizando o curso por correspondência que o habilitou a trabalhar como mecânico especializado em compressores. Mas a empresa explorou essa qualificação sem compensá-lo da forma que esperava. Teve que reprimir a frustração e a raiva, pois, fora da firma que já o conhecia, não via perspectivas de segurança quanto a manter um emprego.

A segunda determinação a destacar é aquela que se vincula às características da empresa " $L$ " enquanto Organização e, muito especialmente, quanto ao modelo de gestão da força de trabalho adotado pela mesma. Uma hierarquização rígida e a adoção de normas disciplinares fortemente coercitivas impedem a expressão de queixas e reivindicações, levando o Sr. Júlio a grandes esforços de auto-controle emocional, nos quais se sente "engasgado" pelas palavras que não pode deixar fluir de sua garganta. A nível de seu corpo, quando ocorrem "desmaios pelo nervoso" e "cai duro", também expressa a paralisia 
resultante do embate de forças contrárias: seu movimento de revolta, de um lado, e a coação silenciadora, internalizada e transformada em auto-repressão, pelo outro.

O depoimento aponta ainda uma terceira determinação: a posição do Sr. Júlio na hierarquia do setor de manutenção. Essa determinação, em verdade, precisa ser apreendida em seu duplo aspecto:

a) O de ser ele contramestre. Na posição de contramestre, encontrase submetido a pressões conflitantes: as que partem das chefias e as daqueles que são seus subordinados. Portanto, Sr. Júlio se confronta aqui com uma nova contraposição de forças, potencialmente paralisante.

b) Estar inserido dentro do setor de manutenção, onde é responsável por um equipamento essencial ao processo de produção. Deve ser ainda assinalado o fato de ser ele o único mecânico da empresa capacitado para a manutenção dos compressores de ar. O que, se por um lado o faz sentir-se valioso e orgulhoso, pelo outro

Pois, mesmo na ausência da chefia, ele tem presente na própria cabeça um lema internalizado ("a produção não pode parar") $e$ trabalha sob uma pressão de tempo que é simultaneamente "pressão da produção" determina que tenha que estar permanentemente disponível para chamadas de emergência, mesmo durante suas horas de repouso e folgas. Na lógica da empresa, o princípio de que a produção não pode

parar se sobrepõe às necessidades e limites da condição humana do agente da manutenção, conduzindo a uma prática em que não ocorrem pausas, as refeições são sacrificadas, os ritmos se aceleram e a jornada se prolonga até que seja sanado o mal que interrompeu a produção. Numa escala de valores onde o desgaste do mecânico é aspecto minimizado.

Para entendimento do processo de constituição do sofrimento psíquico do entrevistado, além destas determinações, é também imprescindível reconhecer a sucessão de perdas que emergem deste histórico que nos trouxe.

No fluir do tempo, após a primeira grande perda que the levou os dedos, veio a perder grande parte da capacidade auditiva. Quando nos diz que "antes eu era alegre, contador de piadas", está nos mostrando que perdeu também o bom humor, a alegria. Sua participação social foi também se restringindo, pois sua sociabilidade foi sendo prejudicada pelo cansaço, pelo desânimo e pela irritação. A ponto de acarretar também perdas significativas na qualidade do relacionamento familiar. Assim, gradualmente, mutilações sucessivas atingiram o corpo, a vida mental e o espaço relacional do Sr. Júlio.

\subsection{Organização e ambiente de trabalho}

Esses aspectos estão fundamentalmente sobredeterminados pela caracterização da empresa "L" como organização e sua política de pessoal.

$\mathrm{O}$ relato do $\mathrm{Sr}$. Júlio permite reconhecer as interações pelas quais diferentes aspectos organizacionais e ambientais do trabalho convergiram para construir seu cansaço e sua tensão nervosa. 
As longas jornadas, o regime de turnos alternados, as pausas insuficientes para o descanso, as pressões e a responsabilidade cotidianas, tudo isto convergiu para aumentar sua sobrecarga de trabalho, por conseguinte, sua fadiga e seu desgaste ao longo dos anos de trabalho na Siderúrgica " $\mathrm{L}$ ".

O entrevistado contou como sua irritabilidade foi sendo exacerba$\mathrm{da}$, simultaneamente, pelo calor, pelo barulho, pelas vibrações (trepidação). Falou-nos também de um "abafamento" de dupla face, expresso ao mesmo tempo por um ambiente físico onde o ar era insuficiente $e$ por uma situação funcional em que vivenciava outro tipo de abafamento: aquele que impedia a expressão de sua irritação e revolta. Em diferentes trechos da entrevista mencionou as pressões a que se sentira submetido. A "pressão de chefia" se confunde por vezes com a "pressão da produção", porém nem sempre. Pois, mesmo na ausência da chefia, ele tem presente na própria cabeça um lema internalizado ("a produção não pode parar") e trabalha sob uma pressão de tempo que é simultaneamente "pressão da produção". Pois sabe que a continuidade da produção depende do equipamento a ser reparado.

Outro aspecto relevante diz respeito à falta de promoção, como veremos adiante.

\subsection{Defesas psicológicas}

Mecanismos psicológicos de defesa costumam ser acionados pelas pessoas sempre que é necessário lidar com angústia ou suportar situações externas capazes de gerar sofrimento psíquico. ${ }^{16}$

Nos processos mentais humanos têm sido estudados diferentes mecanismos de defesa, valendo destacar negação, a auto-repressão, a racionalização, diferentes formas de fuga ou evitação, o deslocamento e a idealização. Considera-se que prejuízos importantes para a saúde mental podem advir do uso constante e exarcebado destes mecanismos. Por outro lado, eles fazem parte da vida mental, sendo importantes na auto-proteção contra o mal-estar psíquico. A sublimação é reconhecida como um mecanismo de elevada importância na preservação da saúde mental, sendo que esta mesma sublimação se associa, fundamentalmente, ao exercício de atividades laborais significativas. ${ }^{17}$

A análise da entrevista do Sr. Júlio possibilita identificar o modo pelo qual alguns mecanismos psicológicos de defesa foram utilizados pelo mesmo.

A repressão de seus sentimentos de revolta e mágoa foi um mecanismo adotado durante muito tempo. Foi certamente o temor de perder o emprego ou de ser seriamente prejudicado em suas relações com as chefias o que presidiu ao intenso esforço de auto-controle emocional de que nos fala. E como não podia extravasar sua raiva e indignação no local de trabalho realizou o deslocamento de sua irritação para o ambiente familiar. Aí o barulho e mesmo a música, surgiram como importantes "detonadores" de suas explosões domésticas. Explosões que provocaram conflitos dolorosos e desespero, em uma dinâmica que, além de ocasionar sofrimento também à família, gerou sentimentos de culpa que agravaram a perturbação psíquica do próprio Sr. Júlio.

A medida que foi progredindo o desgaste mental, a auto-repressão foi se tornando um recurso defensivo cada vez menos eficaz. O próprio auto-controle, exacerbado, passou a funcionar incrementando a tensão nervosa.

O esforço desenvolvido e as pressões enfrentadas ao longo de 47 horas desencadearam o colapso final de sua já enfraquecida defesa. Pois
16. FREUD, Anna. $O$ ego e os mecanismos de defesa, Rio de Janeiro, Biblioteca Universal Popular, 189 págs, 1968; HARTMANN, Heinz. Psicologia do ego e o problema da adaptação. Rio de Janeiro, Biblioteca Universal Popular, 103 págs. 1968.

17. DEJOURS, C., DOPPLER, F. e LOGEAY, P.Op. cit. 
foi no momento da crise que se rompeu a couraça da auto-repressão e eclodiu a explosão dos sentimentos abafados.

Tudo indica que por muito tempo o Sr. Júlio procurou negar a extensão da exploração de que era alvo pela empresa.

Por outro lado, a importância e valorização conferidas à sua especialização como mecânico de compressores constituíram motivos de satisfação e orgulho que contribuíram para fortalecer seu ânimo e sua auto-imagem. Essa vivência de auto-realização foi intensificada também pelo fato de ter atuado "como um professor", transmitindo a outros seus conhecimentos e práticas especializados. Muito embora, mais tarde, tenha experimentado profunda mágoa pelo que sentiu como imensa decepção e injustiça para com seus méritos: seus discípulos foram promovidos, passaram a receber melhores salários do que ele e alguns se tornaram seus superiores hierárquicos. Entretanto, seu depoimento transmite a idéia de que o $\mathrm{Sr}$. Júlio havia, durante bastante tempo, mantido altas esperanças de ter seus esforços reconhecidos e recompensados, dentro de uma empresa que inicialmente visulizara como "boa" e "justa", através de seus mecanismos psicológicos de idealização.

\section{Breve estudo do apoio familiar e das resistências}

Ao lado dos elementos e aspectos identificados como adoecedores, há que buscar, também, a compreensão das resistências individuais e coletivas, suporte ou estruturas de apoio informal. Comecemos no caso do Sr. Júlio, por algumas considerações sobre a instância familiar, que se constituiu, de acordo com a entrevista, um suporte importante.

\subsection{O apoio familiar}

O ambiente familiar foi o único lugar para onde o Sr. Júlio pôde dar evasão às manifestações de sua ansiedade. O deslocamento da expressão de sua raiva, do local onde essa sua revolta era suscitada para sua própria casa, se constituiu, nas palavras do Sr. Júlio, em algo "traumatizante".

Entretanto, foi também sua familia que o ajudou a suportar as tensões decorrentes de seu trabalho, na medida em que lhe deu apoio afetivo.

Num momento de grande emoção, dirigindo-se à família durante a entrevista, o Sr. Júlio expressou o quanto se sentira apoiado pela ajuda e pelo carinho recebidos. Demonstrou, assim, como esse mesmo apoio foi importante para a resolução da fase mais aguda de sua perturbação mental quando necessitou inclusive do acompamento de seus familiares para lidar como os sintomas fóbicos (o medo de andar na rua sozinho) que o acometeram.

Uma análise mais profunda seria necessária, para dar melhor conta de toda a complexidade das inter-relações família-trabalho e da forma como a vida psíquica e as relações intra-familiares sofrem as repercussões indiretas da experiência laboral do trabalhador entrevistado.

\subsection{Resistência individual}

Ocorreu alguma resistência individual do $\mathrm{Sr}$. Júlio à estrutura e aos poderes que o superexploravam. Essa resistência, dentro de um sistema fortemente autoritário e repressor, foi a princípio sutil, exercendose através das tentativas de, usando sua inteligência e o estudo, quali- 
ficar-se e assumir funções mais valorizadas e menos penosas. $O$ êxito não foi suficiente, logo percebeu que sua nova capacitação também passava a ser superexplorada.

Mencionou ainda alguns protestos e reclamações que realizou, como no caso em que denunciou o risco representado pelo depósito de ar na sala dos compressores. Falou também de ter sido solidário, testemunhando a favor de operários prejudicados pela empresa e ensinando "os direitos que o operário tem".

2.3. Resistências coletivas. Comentário sobre sua ausência no relato do Sr. Júlio.

O relato deixa de mencionar as resistências organizadas do coletivo de trabalhadores da empresa siderúrgica em que o entrevistado havia trabalhado. Nesta empresa, entretanto, por muitos anos ocorreram fortes movimentos dirigidos a reivindicar direitos negados pela mesma - como a remuneração dos domingos e das horas-extras trabalhadas em conformidade com a legislação - e a instalação de refeitórios, por muito tempo inexistentes na empresa.

Ocorre a possibilidade de que a posição de contra-mestre, alida à vulnerabilidade que sentia por ser mutilado, tenham influído para que o entrevistado não tivesse estado mais próximo de tais resistências e por.isso não as tenha mencionado. Por outro

A diversidade das situações de trabalho e as rápidas mudanças tecnológicas e organizacionais dos processos em que se insere a atividade laboral, exigem que a identificação das circunstâncias tensiógenas seja realizada de forma continuada, com participação dos que trabalham nos setores pesquisados. lado, essa falta de participação pode talvez ser relacionada, também, no próprio cansaço e desânimo vivenciados. Vale lembrar, a propósito, a importância que pode ser atribuída à fadiga na constituição do processo de alienação.

\section{Três questões de ordem prática}

a) A questão do diagnóstico

Do ponto de vista das regras institucionalizadas nos serviços médicos, há exigência de que o médico registre um parecer diagnóstico. $O$ desafio é integrar adequação científica e responsabilidade social, quando casos como o do Sr. Júlio são atendidos, seja pelo consultante, seja pelo perito. Certamente os desafios colocados ao médico serão diferentes conforme o tipo de serviço e a função exercida pelo mesmo.

Mas em qualquer situação, precisa ser evitada a utilização de rotulações diagnósticas genéricas e vagas - como "D.N.V." (distonia neurovegetativa) ou "agitação psicomotora" - e mesmo de diagnósticos psiquiátricos cujo enunciado não revele os aspectos laborais na origem do quadro clínico. Por exemplo, aplicar ao Sr. Júlio um diagnóstico mais tradicional de "psiconeurose mista" ou de "neurose conversiva com componentes fóbicos", constituiria um modo de ocul- 
tar o vínculo da sintomatologia com a instância trabalho. Felizmente as classificações mais recentes dos distúrbios mentais já incluem categorias que permitem registrar o caráter reativo da sintomatologia e mesmo, o assinalamento do tipo de situação envolvida (laboral, familiar, escolar etc).

Assim, mesmo considerando a especificidade dos aspectos individuais presentes em qualquer situação de adoecimento, fica aí assegurada a refêrencia à determinção laboral.

b) A questão terapêutica

Atendido em sua "crise de nervos", o Sr. Júlio recebeu medicação tranqüilizante, sendo posteriormente atendido regularmente por um psiquiatra que, num processo de psicoterapia, conduziu-o tanto à remissão dos sintomas quanto a uma visão mais clara do que havia ocorrido consigo. Foi assim que pôde perceber a extensão em que sua auto-repressão - ou, como o disse, seu "abafamento" - contribuiu para a eclosão da crise aguda. Posteriormente, mudou sua atitude diante das pressões do trabalho. Por exemplo, a próposito da antes aflitiva situação de falta de peças, perdeu o receio de verbalizar, já não se angustiava por ter que improvisar peças "novas" de modo precário, e passou a exigir o material necessário ao seu serviço.

Não obstante, torna-se evidente que há um grande limite para qualquer ação terapêutica eficaz, sempre que inexistir uma transformação efetiva da situação de trabalho vinculada à constituição do sofrimento mental, e, portanto, o reconhecimento da dimensão coletiva daquilo que o origina.

\section{c) A questão preventiva}

A magnitude do desafio preventivo certamente não poderá ser analisada neste pequeno espaço, uma vez que passa pela complexidade da dinâmica originadora dos distúrbios e, portanto, obrigatoriamente, pela organização do trabalho.

A diversidade das situações de trabalho e as rápidas mudanças tecnológicas e organizacionais dos processos em que se insere a atividade laboral, exigem que a identificação das circunstâncias tensiógenas seja realizada de forma continuada, com participação dos que trabalham nos setores pesquisados. ${ }^{18}$

Do mesmo modo, essa participação será necessária para definir e implementar medidas preventivas integradas às transformações do trabalho que terão este caráter.

O objetivo preventivo pode ser confrontado por objeções associadas ao temor de incremento de custos. Nestas discussões, convirá lembrar sempre, ao lado dos argumentos de ordem ética, que também do ponto de vista econômico, o interesse em investir no capital humano exige ser seriamente considerado pelas empresas.

A informação em Saúde Mental do Trabalho, desse modo, passa a

18. DEJOURS, Christophe. "Itineraire Theorique on Psychopathologie du Travail", Op. cit. ser instrumento importante, tanto para representantes da empresa quanto para representantes dos empregados, por ocasião das negociações que buscam harmonizar os objetivos econômicos e a humanização do trabalho. 